\title{
Long-term trends of heron and egret populations in Italy, and the effects of climate, human-induced mortality, and habitat on population dynamics
}

\author{
Mauro Fasola $\cdot$ Diego Rubolini $\cdot$ Enrico Merli $\cdot$ \\ Eleonora Boncompagni · Umberto Bressan
}

Received: 17 December 2008/ Accepted: 5 May 2009/Published online: 10 July 2009

(C) The Society of Population Ecology and Springer 2009

\begin{abstract}
Factors affecting bird population dynamics include climate, harvesting by humans, and habitat changes. Here, we describe the long-term (1972-2006) population trends of seven heron species in NW Italy, an area holding important European breeding populations of these species. Grey (Ardea cinerea), purple (Ardea purpurea), and squacco (Ardeola ralloides) herons, and little egrets (Egretta garzetta) exhibited a strong logistic increase, leveling off around year 2000 at 3-23 times their initial level. Black-crowned night herons (Nycticorax nycticorax) began by increasing like the former species but then dropped to initial levels. Such trends were found to be influenced by several candidate ecological factors, as assessed by ARIMA models. Specifically, grey herons increased following a decrease in human-induced mortality, as quantified by an index of hunting pressure, and an increase in winter temperatures. Little egrets increased mainly with the increase of the extent of ricefields, whereas squacco herons increased with increasing rainfall in the African wintering range.
\end{abstract}

Electronic supplementary material The online version of this article (doi:10.1007/s10144-009-0165-1) contains supplementary material, which is available to authorized users.

M. Fasola $(\bowtie) \cdot$ E. Merli · E. Boncompagni

Dipartimento di Biologia Animale, Università degli Studi di

Pavia, Piazza Botta 9, 27100 Pavia, Italy

e-mail: fasola@unipv.it

D. Rubolini

Dipartimento di Biologia, Università degli Studi di Milano, via Celoria 26, 20133, Milan, Italy

e-mail: diego.rubolini@unimi.it

U. Bressan

Direzione Generale Qualità dell'Ambiente, Regione Lombardia,

Via Taramelli 12, 20125 Milan, Italy

e-mail: umberto_bressan@regione.lombardia.it
Black-crowned night herons were also positively affected by increasing African rainfall, but only during 1972-1988, whereas in later years competition with other herons could have affected the species' decline. The improved protection of colony sites by special reserves was unlikely to be the primary trigger of the observed increase, although obviously important for the long-term population persistence. In conclusion, our study shows that heron populations of southern Europe are sensitive to environmental and climatic changes, as well as to temporal variation in human disturbance and changes in foraging habitats, though the importance of the different factors differs among species.

Keywords Ardeidae - Climate change - Conservation . Hunting mortality $\cdot$ Population trends $\cdot$ Ricefields

\section{Introduction}

Understanding how and why animal populations fluctuate is a major topic in ecology, and bird species have been the subject of considerable research efforts (summarized by Perrins et al. 1993; Newton 1998). Several natural processes (e.g., density-dependence, environmental stochasticity, competition) and their interactions may affect avian population dynamics (Bethke and Nudds 1995; Newton 1998; Lande et al. 2003; Viljugrein et al. 2005; Sæther et al. 2008). In addition, human-induced environmental changes (e.g., habitat modification, hunting) have been directly or indirectly related to population trends, often becoming an issue of conservation concern (e.g., McCulloch et al. 1992; Tucker and Heath 1994; review in Newton 1998; Donald et al. 2001; Stenseth et al. 2002; Gaston et al. 2003; Duhem et al. 2008).

Here, we describe the results of a large-scale, long-term monitoring program (1972-2006) of the populations of 
seven colonial heron and egret species (grey heron Ardea cinerea, purple heron A. purpurea, little egret Egretta garzetta, squacco heron Ardeola ralloides, black-crowned night heron Nycticorax nycticorax, great egret Ardea alba, and cattle egret Bubulcus ibis) breeding over a wide area of NW Italy. We attempted to identify the role of some natural and human-mediated extrinsic factors in driving the observed population trends. The ricefields of NW Italy, the largest extension of rice cultivation in Europe, host heron populations of continental importance (up to $15 \%$ of the total European population for the little egret and the blackcrowned night heron; Fasola and Ruiz 1996a, b).

We hypothesized that heron population trends may be affected by (1) climatic fluctuations both in the wintering areas (rainfall) and in the breeding areas (temperature, rainfall); (2) changes in human-induced mortality, defined as an estimate of the human pressure on heron populations due to hunting, shooting or trapping; and (3) changes in the availability of ricefields, i.e., the main foraging habitat of heron species in the study area. Finally, at a colony-level scale, we (4) addressed the effects of changes in colony legal protection status and main habitat surrounding colony sites on population trends. Below, we outline the rationale behind these hypotheses, and formulate some general predictions based on current knowledge.

Climatic variation, including ongoing climatic changes, is of utmost importance in determining demographic traits, population trends, and distribution of bird species (Bethke and Nudds 1995; review in Stenseth et al. 2002; BöhningGaese and Lemoine 2004; Crick 2004; Sæther et al. 2004; Both et al. 2006; Møller et al. 2008; Reif et al. 2008; Seavy et al. 2008). Climate variation may influence bird populations both in their breeding and non-breeding areas, by affecting important demographic processes such as breeding success and survival (reviewed in Newton 1998; Lande et al. 2003). Previous studies of herons have shown that cold winters reduce breeding numbers of resident or partially migratory species (e.g., cattle and little egrets, grey heron; Hafner et al. 1992, 2002; Marchant et al. 2004), due to lower overwinter survival of first-year birds (North and Morgan 1979). Early spring rainfall was also shown to positively affect breeding success and breeding numbers of little egrets in natural coastal wetlands (Bennetts et al. 2000; Hafner et al. 2002). Moreover, reduced rainfall in the sub-Saharan winter quarters negatively affects population size of migrant species (e.g., purple heron, black-crowned night heron), because of decreasing wetland extent and food supplies, resulting in reduced survival and lower numbers of breeders in Europe (Fasola et al. 2000; Barbraud and Hafner 2001). We therefore predicted that populations of resident species should be positively affected by mild winters and abundant early spring rainfall, while populations of migratory species should be negatively affected by low African rainfall.
Populations of large, slow-reproducing species, including herons, may be specially vulnerable to direct human persecution, including hunting (McCulloch et al. 1992; Newton 1998; Barbosa 2001). The impact of hunting is generally assessed by proxies of hunting pressures based on ring recoveries, such as the 'hunting index' (McCulloch et al. 1992). The hunting index suffers from significant limitations, since it is based on the spontaneous reporting of recoveries by the public, including hunters, and thus changes in hunting pressure through time as assessed by the hunting index may be biased by changes in reporting attitudes, because of, e.g., enforcement of species' protection measures (McCulloch et al. 1992; Barbosa 2001). However, it has been suggested that a temporal decline in the hunting index of protected species may indeed correspond to a decreased impact of direct human persecution following improvement of the legal protection status (Barbosa 2001). In this paper, we describe temporal variation in an index of hunting-related mortality of heron species during the twentieth century, and we test the prediction that heron populations should be positively affected by reduced hunting pressure (Marion 1997).

Finally, bird populations may be affected by large-scale habitat modifications (review in Tucker and Heath 1994). For example, changes in foraging habitats were shown to affect populations of herons and egrets in southern France (Tourenq et al. 2000). In our case, we expected heron populations to be positively influenced by the recent increase in the extent of ricefields that occurred in the study area $(+25 \%$ during 1972-2005, see "Materials and methods"), where ricefields represent the main foraging habitat of most species (Fasola 1986, 1994).

Heron populations of NW Italy enjoy a satisfactory level of protection, due to the enforcement of site-specific conservation actions targeting the largest colonies (Fasola and Alieri 1992). However, not all colonies are located in protected areas, and the protection status of many colonies has changed in the course of the study period. We therefore examined whether population trends at the colony-level varied according to colony protection status. We expected that colony protection should result in more favorable population trends. Moreover, we expected colonies settled in the most suitable habitat (i.e., ricefields) to show more favorable trends compared to those settled in other, potentially less suitable, habitats.

\section{Materials and methods}

Study species

Five species bred throughout the entire study period (grey heron, purple heron, little egret, squacco heron, and black- 
crowned night heron), while the great egret and the cattle egret started breeding only recently (Fasola et al. 2007). These seven species breed syntopically in Italy, often in mixed colonies, but differ in other characteristics that may influence their populations, such as their foraging niches (Fasola 1986, 1994), as well as their migratory habits (Cramp and Simmons 1977; Fasola and Hafner 1997; Hafner et al. 2002). The grey heron and the cattle egret are mostly resident within their breeding range in NW Italy, and moderately migratory and dispersive. The great egret and the little egret are partially migratory and dispersive within the Mediterranean, the latter with an unknown portion of trans-Saharan migrants. An increasing portion of the two latter species winters within the breeding range (recently $12 \%$ of the little egrets in Northern Italy and $30 \%$ in southern France, Hafner et al. 2002). Conversely, the purple, squacco, and black-crowned night heron are mostly sub-Saharan migrants that winter from October to March in tropical Africa.

Study area, heronries and census effort

Breeding heron populations were monitored from 1972 to 2006 throughout NW Italy (Fig. 1), including the Lombardy and Piedmont regions, and the provinces of Piacenza, Parma, and Reggio Emilia, an area of $57,591 \mathrm{~km}^{2}$ where herons are particularly abundant (Fasola and Ruiz 1996a, b) thanks to the large surfaces of ricefields $\left(2,114 \mathrm{~km}^{2}\right.$ in
2005; data from the Ente Nazionale Risi, website, http://www.enterisi.it/index.jsp). From 1972 to 2006, we recorded 180 breeding sites of herons and egrets. Most heronries were stable, and some have been known for more than a century (Moltoni 1936). The heronries were located in wetlands with alder woods, bushy willows, and reed beds, or dry mature woodlands, false acacia groves, and poplar plantations (Fasola et al. 2007). The total number of active heronries increased from 40 in 1972 to 110 in 2006, keeping the pace of the population increase. In 2006, the total number of nests was as follows: grey heron, 9,481; purple heron, 435; great egret, 15; little egret, 9,551; squacco heron, 165; cattle egret, 516; black-crowned night heron, 7,629.

Complete censuses at all the heronries were accomplished in 1981, 1986 and 2002, while a large sample of heronries were censused in all the other years, except for 1972 when counts were limited to few sites [see Fig. S1 in Electronic supplementary material (ESM)]. Even when nests were not counted, breeding was confirmed for each species, colony and year, thus providing important information for calculating a population index. Such incomplete counts, requiring the adoption of population indexes, are typical in large-scale censuses of colonial birds (e.g., the grey heron in the UK; Marchant et al. 2004). Thorough details on census techniques and sampling effort are reported by Fasola et al. (2007) and in the ESM.

Fig. 1 Study area in NW Italy with all the heronry sites recorded from 1972 to 2003, in the "ricefields" (open circles), in the "rivers" (grey circles) and in the "upland" (black circles) sectors, and in four classes of average number of nests (small circles $\leq 50$ nests, medium 51-100, large 101-250, largest $>250$ )

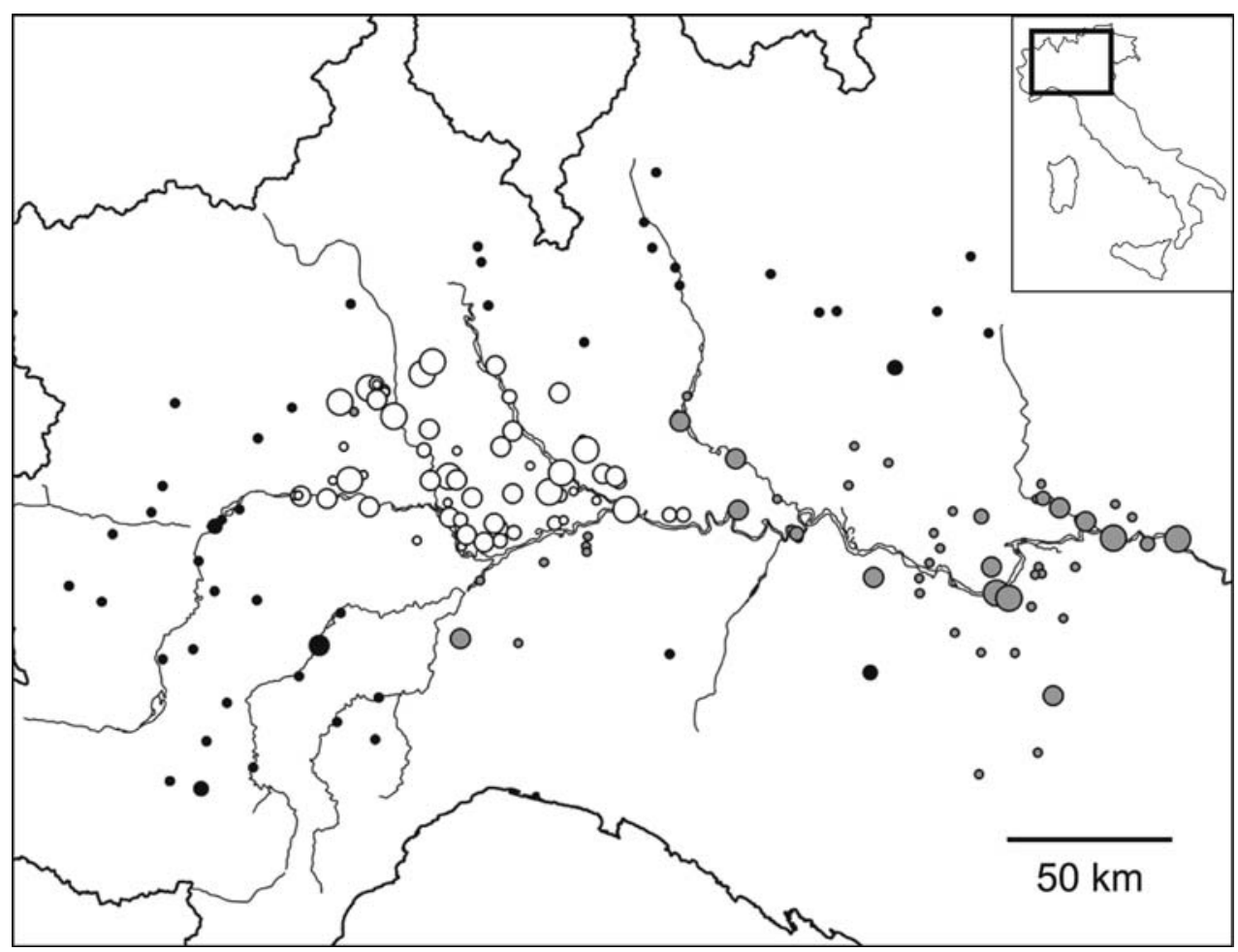


Population trend analysis

Annual changes in the overall breeding population levels of heron species was computed as the ratio between the population size in each given year and that of year 2000 . To reduce the effects of missing values (colonies not monitored in a specific year) on the accuracy of population estimates, the index was computed using the loglinear Poisson regression method as implemented by the TRIM software (Pannekoek and van Strien 2001). This software was specifically developed to analyze monitoring data from incomplete counts, which is commonplace in ecological surveys, and it accounts for typical overdispersion and temporal autocorrelation of such data (van Strien et al. 2004). TRIM models can take into account "change points", i.e., years when the overall trend of a series changes, and "categorical covariates", i.e., factors that group individual sites on the basis of a feature hypothesized to affect population trends. The final result is a model, or a combination of functions if categorical covariates and change points are taken into account, whose yearly values ( $Y_{i}$, for the $i$ th year) can be used to predict missing counts in the census time series. This procedure originated an imputed series of the index whose yearly values $\left(I_{i}\right)$, in our case, were computed from the sum of nests for each colony that had been actually observed, or that had been estimated for the colonies not monitored in a given year.

We used categorical covariates as a tool to group colonies in homogeneous subsets. Covariates were retained if they improved the estimates of the model index. With this purpose, colonies were categorized according to the main surrounding habitat ("habitat" covariate), and each colony site and year was assigned a dichotomous "protection" covariate. The "habitat" covariate had three levels: "ricefields", "rivers" and "upland". "Ricefields" identified the 64 heronries located in lowlands with abundant ricefields, where all the species have bred since the 1970s. "Rivers" identified the 52 heronries located in lowlands along rivers, where an increasing number of herons appeared only after the 1980s, and hosted colony sites that were subjected to some turnover. "Upland" identified the 42 heronries located in areas of higher elevation, from 250 to $650 \mathrm{~m}$ a.s.1., that were colonized only after the 1990s (Fig. 1). A "non-protected" status was maintained by 99 sites throughout the entire period. Two sites since 1972, 8 sites since 1977, 5 sites since 1979, 29 sites since 1985, and 15 sites since 1990 attained the legal status of nature reserves and enjoyed some form of effective protection, being thus categorized as "protected" after those years.

The best model for each series, among those that differed in the number and location of change points and in the role of covariates, was selected by the modified AIC or
AICc (Burnham and Anderson 2002), without accounting for the statistical significance of the models or of the parameter estimates, which are sensitive to the sample size and uninformative for modelling purposes (Johnson 1999; Anderson et al. 2000). All the TRIM models achieved a poor fit, because individual heronries may fluctuate opposite to the general trend, e.g., one heronry may decrease or disappear for extrinsic reasons (such as habitat destruction) while the global population increases strongly, and also because of the large number of degrees of freedom for the goodness-of-fit test (from a minimum of 171 for the great egret model, to a maximum of 3,590 for the grey heron one). However, a poor model fit can be ignored in the calculation of the TRIM Imputed index (Pannekoek and van Strien 2001).

In order to describe the shape of the time series at the entire population level, we fitted four models (linear, quadratic, exponential, and logistic growth) to population indexes by regression analyses with year as predictor. Model selection was based on the AICc.

Factors affecting population dynamics

\section{Climatic variables}

Based on previous research on factors affecting heron populations (see "Introduction"), we selected as potentially relevant climatic variables the local rainfall before the breeding season, that may affect breeding numbers, and the climatic conditions in the wintering areas during the previous winter, that may affect the survival of potential breeders.

As an index of pre-breeding rainfall in the study area, we considered the average monthly rainfall anomalies from January to April ("Rain Italy"), expressed as anomalies in $\mathrm{mm}$ within the area $45^{\circ}-46^{\circ} \mathrm{N}, 8^{\circ}-11^{\circ} \mathrm{E}$ (data obtained from the National Climatic Data Center-NCDC-website, http://www.ncdc.noaa.gov, GHCN precipitation dataset). This variable could be hypothesized to mostly influence resident or semi-resident species, and it was therefore considered as a candidate covariate in the ARIMA models (see below) for the grey heron and little egret only.

As a descriptor of the climatic conditions that may affect winter survival of resident species, we considered the mean temperature anomalies of January-February in the study area ("Winter Temperature Italy"). Anomalies were obtained from the area $45^{\circ}-46^{\circ} \mathrm{N}, 8^{\circ}-11^{\circ} \mathrm{E}$, also from the NCDC website). This variable was considered as a candidate covariate in the ARIMA models for the grey heron and the little egret only.

As descriptors of climate in the areas of sub-Saharan West Africa where some European heron species 
overwinter, we considered: (1) an index of rainfall in the Sahel for the period September-December of year $(n-1)$ ("Rain in Sahel"), and for the area $10^{\circ}-20^{\circ} \mathrm{N}, 20^{\circ} \mathrm{W}-10^{\circ} \mathrm{E}$ (data obtained from the Joint Institute for the Study of the Atmosphere and Ocean website, http://jisao.washington. edu/data_sets/sahel); and (2) rainfall anomalies (in $\mathrm{mm}$ ) in the sub-Saharan West Africa ("Sub-Saharan Rain") for the period September-December of year $(n-1)$, and for the area $5^{\circ}-17^{\circ} \mathrm{N}, 17^{\circ} \mathrm{W}-4^{\circ} \mathrm{E}$ (from the NCDC website). The amount of rainfall in West Africa could affect purple, squacco, and black-crowned night herons, mostly subSaharan migrants to a wintering range including the countries west to east from Senegal to Nigeria, and south to north from Ghana to Mali (Cramp and Simmons 1977; Fasola and Hafner 1997; van der Winden et al. 2008; M. Fasola et al., unpublished analysis of EURING database). Since the precise limits of the winter range of these species, as well as their ecology in West Africa, are still poorly known, both variables were considered as potential candidate covariates in the ARIMA models for these three species.

\section{Human-induced mortality}

We obtained from the EURING databank all the available records (from 1908 to 2006) of ringing and subsequent recovery of the grey heron $(35,109$ records), purple heron $(2,059)$, squacco heron $(187)$, cattle egret $(1,680)$, great egret (438), little egret $(1,549)$, and black-crowned night heron (962). The proportion of birds intentionally killed by man in a given year ("human-induced mortality") was calculated by a method similar to that used by McCulloch et al. (1992) and Barbosa (2001):

human-induced mortality index

$=$ number of birds "hunted",/total birds found.

We included in the "hunted" category all the birds whose finding circumstances were coded from 10 to 22 by EURING (Speek et al. 2006), i.e., all the birds shot, hunted by any means, and trapped intentionally by man, either legally or illegally, and for any reason. The category "Found" included all the birds that were recovered with "Circumstances" coded from 0 to 78 , but we excluded from the dataset the recoveries with "Circumstances" coded 0 or 1 and with "Conditions" coded 0 or 1 , because the circumstances and date of death could not be correctly identified for these recoveries. The values of the "humaninduced mortality" index were calculated initially from the entire dataset available for each species. For the grey heron, which had sufficient data, separate indexes were also calculated for Africa, southern Europe (including Portugal, Spain, France, Italy, and Balkan peninsula including Romania), central Europe (including
Switzerland, Austria, Czech Republic, Germany, Poland, Denmark, and Benelux), and Northern Europe (including Ireland, UK, Estonia, Latvia, Lithuania, Finland, Sweden, and Norway) in order to explore geographic variation in hunting pressure. The "human-induced mortality" index is certainly exposed to several possible biases (including changes in reporting attitudes of species becoming legally protected; see thorough discussion in McCulloch et al. 1992). Thus, the "human-induced mortality" index cannot be regarded as an accurate estimate of the proportion harvested. Nonetheless, its changes are at least partially attributable to real changes in direct human persecution (Barbosa 2001), and can therefore be used to estimate human-related mortality with a sufficient accuracy for correlative analyses.

Temporal variations of the "human-induced mortality" index were analyzed using weighted least-squares analysis of covariance models. As dependent variable, we included a 5-year cumulative human-induced mortality index starting from 1926, when the temporal series begun to be relatively continuous. In order to describe the long-term trends in human-induced mortality, we first performed separate linear regression models for each species (except for the grey heron, see below), with 5-year periods as the independent variable. Non-linear terms did not fit significantly better than linear ones, and were thus excluded from further analyses (details not shown). For the grey heron only, thanks to its large sample size, we could check for among-areas differences in human-induced mortality, by including geographic area as a fixed effect factor (see above). The year $\times$ area interaction was included in order to test for differences among geographic areas in changes of the human-induced mortality index through time.

In the models, each datum was weighted according to the relative proportion of recoveries contributing to the calculation of the human-induced mortality index in a given geographical area (WLS option in the GLM command of the SPSS 13.0 software). Such weighting was based on the assumption that the accuracy of the humaninduced mortality index should be proportional to the number of recoveries contributing to it. We adopted proportional, rather than absolute, weights to take into account the remarkable differences in the sample size of recoveries between the different species or geographical areas. In any case, only 5-year periods with at least 5 recoveries were included in the analyses. The human-induced mortality index was expressed as a proportion, but for ease of interpretation of temporal changes it was treated as a continuous variable. The distribution of the human-induced mortality index for each species did not significantly deviate from normality, and all model residuals did not deviate significantly from normality (Kolmogorov-Smirnov tests, all $P>0.17$ ). 
The effects of temporal variation in human-induced mortality on population trends were analyzed by including the human-induced mortality index as a candidate covariate in the ARIMA models (see below). For the grey heron, the sample of the EURING recoveries was large enough to estimate yearly values for the index, whereas for the other species we combined all the recovery data for all species (including the grey heron) to obtain a general estimate of their yearly human-induced mortality index. For the grey heron, a species widespread throughout Europe, we considered as a candidate covariate for the ARIMA models the mortality values for Southern Europe only, while for the other species that breed mostly within Southern Europe, we used the overall values.

\section{Foraging habitats}

No major wetland reclamation occurred during our survey. Therefore, a major change in foraging habitat availability could only concern ricefields, which support $80 \%$ of the foraging herons and egrets (Fasola and Ruiz 1996a), and which are subject to rotation with dry crops and also may change in extent due to market demands. The total surface area of ricefields within our study area was calculated for each year of study with hectare accuracy (from the data on the Ente Nazionale Risi website, see above).

\section{Relationships of population fluctuations with climate, human-induced mortality, and changes in foraging habitat}

We evaluated the effect of the three main hypothesized factors of population change (i.e., climate variation, humaninduced mortality, and foraging habitat availability; see above) on population trends of each species. Analyses were not performed for the two recent colonizers, the great egret and the cattle egret, whose times series were too short.

The population trend of each species was described by the TRIM Imputed index. We analyzed the relationships between this index and the selected candidate predictor variables for the selected species using ARIMA models, built and selected following the procedures outlined in Box and Jenkins (1976). As a first step, aimed at identifying the time lag between the effects of candidate predictors and population numerical responses, TRIM residuals (TR) and the annual proportional increase index (APII) were calculated as follows:

$\mathrm{TR}_{i}=I_{i}-Y_{i}$

$\mathrm{APII}_{i}=\left(I_{i+1}-I_{i}\right) / I_{i}$

where $I_{i}$ was the Imputed index of population trend for the $i$ th year (see "Population trend analysis" above, for details) and $Y_{i}$ was TRIM model index. These two variables, representing population changes after removing serial dependency, were analyzed for cross-correlation with candidate predictors, in order to define potential lags in association, until a maximum lag of 5 years. Candidate predictors significantly $(P<0.05)$ related to TR or to APII were considered, at the identified lag, as predictors of the TRIM Imputed index $\left(I_{i}\right)$ in the ARIMA models. No models entering two African climate covariates were evaluated, owing to the expected high correlation among predictors and to the subsequent collinearity problems in parameters estimation (Guisan et al. 2002).

Patterns of the estimated autocorrelation and partial autocorrelation function of population indexes were used for ARIMA model identification. A first-order autoregressive model (ARIMA 1,0,0) with a positive coefficient $(\Phi>0)$ was identified for all species. Maximum likelihood methods were used for parameter estimation. Model selection was based on AICc (Burnham and Anderson 2002). In order to better quantify the effects of the predictor variables on each species, the $\hat{B}$ (estimated partial regression coefficients) of the predictors were weighted and averaged on all the models evaluated for the species, thus obtaining the mean estimate $\hat{\bar{B}}$. The relative importance of the predictors was measured by the sum of the Akaike weights of the models $(\Sigma w)$ in which the variable was entered (Burnham and Anderson 2002). All the analyses were carried out by using the SPSS 13.0 software, and the values of the AICc were derived from log-likelihood values by the formula proposed by Burnham and Anderson (2002).

\section{Results}

Population trends

The overall population indexes calculated by the best-fitting TRIM models are shown in Fig. 2. Most species exhibited a strong increase, and for all species the best fitting regression models were highly significant (all $P<0.001$ ) (see Table S1 in ESM for additional details). Notably, the grey heron increased regularly during the 1980s and the 1990s, then since 1998 the population has leveled off at a number of nests 23.5 times greater than the mean number during 1976-1978. A lower but significant increase was also shown by the little egret, whose average population size during 1997-2006 was 4.4 times larger than the 1976-1978 mean. The trends of these two species are well described by logistic models $\left(R^{2}=0.97\right.$ and 0.91 , respectively; Table S1). The purple heron increased as well, the mean number in the last 5 years of the time series being 2.2 greater than that during 1976-1978. Its trend is well described by a quadratic model $\left(R^{2}=0.87\right)$, possibly because its numbers have not yet reached an asymptote 


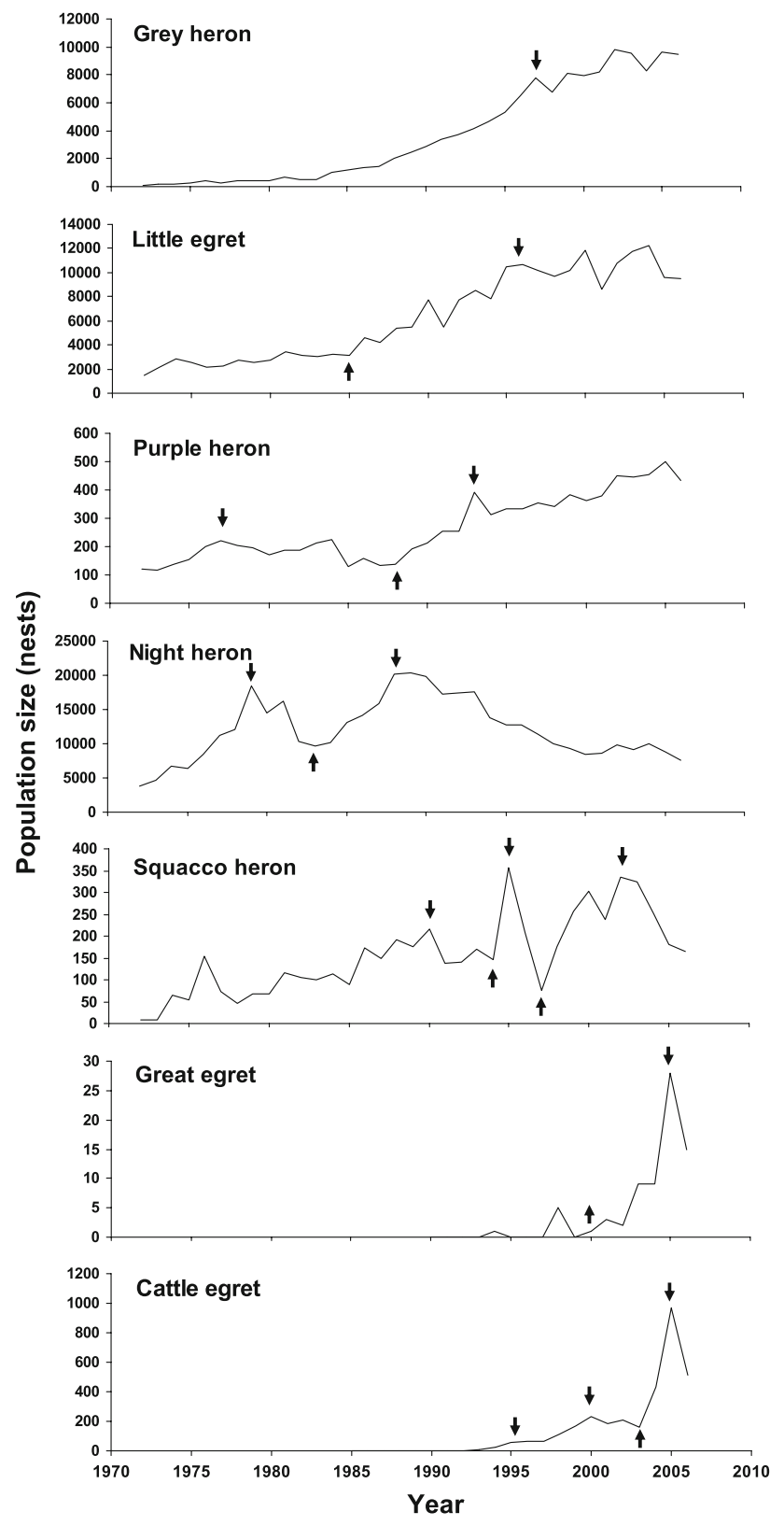

Fig. 2 Trends in population size (estimated number of nests, derived by the TRIM Imputed index; see "Materials and methods") of the seven species of herons and egrets breeding in NW Italy, 1972-2006. The arrows point to years of significant trend change (i.e., change points; see "Materials and methods")

(Table S1). The increase of the squacco heron was mostly described by a linear model $\left(R^{2}=0.60\right.$; Table $\left.\mathrm{S} 1\right)$, and was characterized by conspicuous among-years fluctuations, which could derive from methodological difficulties in the estimation of breeding numbers of this secretive species. The black-crowned night heron increased with the other species during the initial part of our study, peaked in 1989, but then decreased to its initial levels (Fig. 2), a pattern well described by a quadratic model $\left(R^{2}=0.62\right.$; Table S1).
The two new colonizers, the cattle egret and the great egret, that bred for the first time in 1988 and in 1994, respectively, showed a trend that is presumably the initial part of a logistic increase (Fig. 2).

The best-fitting models that were selected by the TRIM software to describe the fluctuations of the five regularly breeding species included the effect of both the "habitat" and the "protection" covariates for four species, and only of the "protection" covariate for the little egret (Table S2 in ESM). The contribution of the covariates enhanced model fitting to the observed data, improving AIC even if in one case the effect of covariates did not reach statistical significance (squacco heron). The TRIM model-predicted population indexes for the separate states of these two covariates are depicted in Figs. 3 and 4 (only when the effect of the covariate was statistically significant), and the population levels (number of nests, derived by the TRIM Imputed index) for each state of the covariates in Figs. S2 and $\mathrm{S} 3$ in ESM.
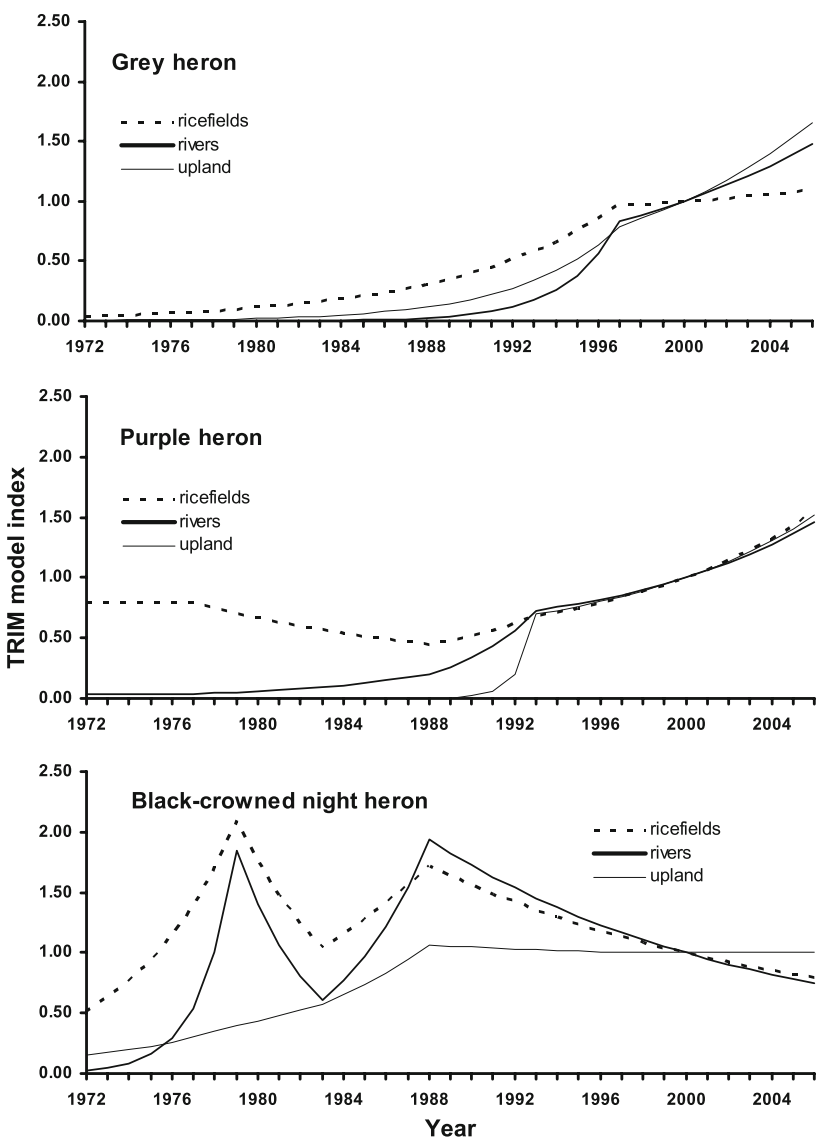

Fig. 3 TRIM model-predicted population indexes for each level of the "habitat" covariate. Graphs are shown only if the effect of the covariate was statistically significant in the TRIM models (see Table S2 in ESM). Values for year 2000 set to 1 by definition 

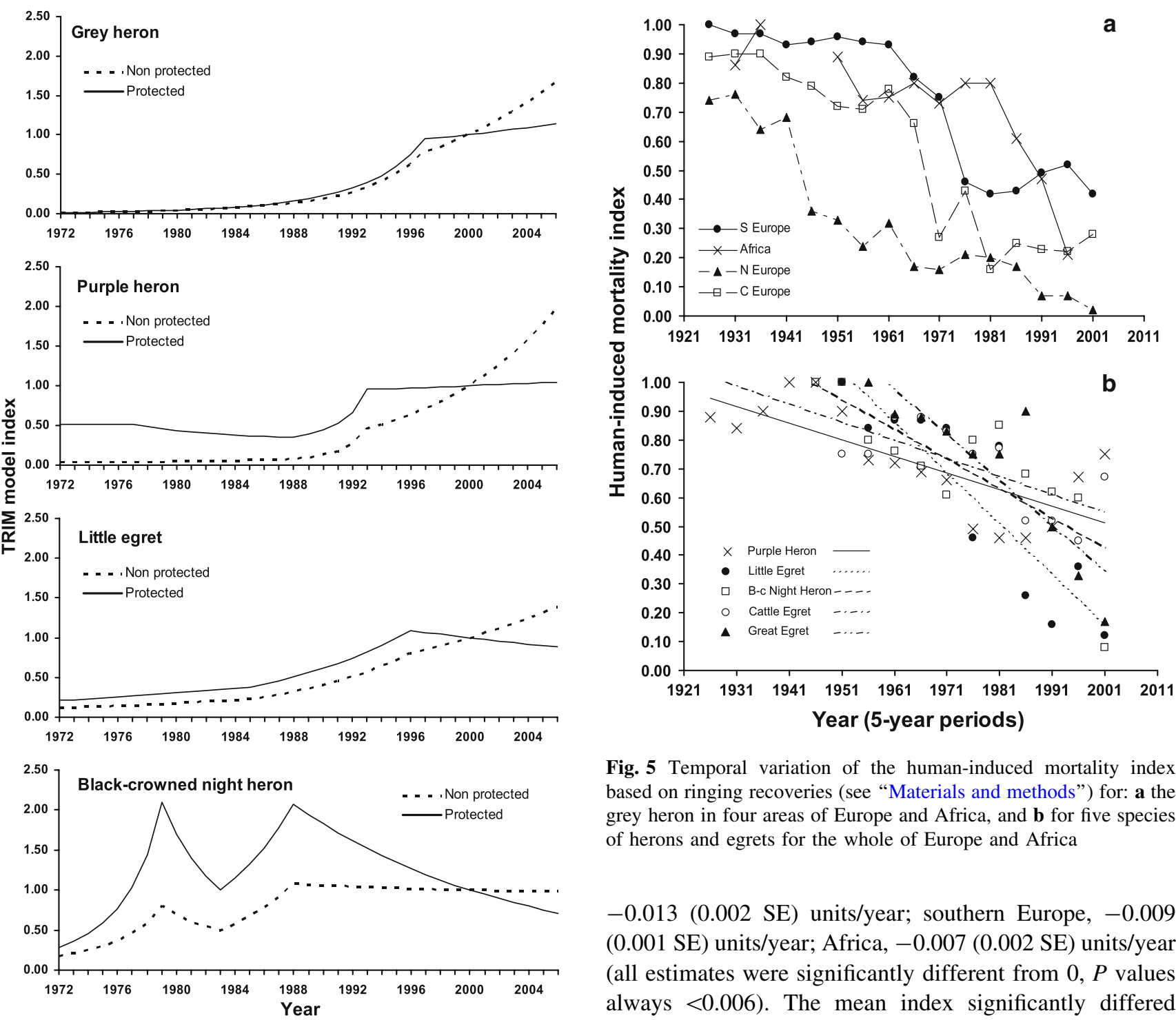

Fig. 5 Temporal variation of the human-induced mortality index based on ringing recoveries (see "Materials and methods") for: a the grey heron in four areas of Europe and Africa, and $\mathbf{b}$ for five species of herons and egrets for the whole of Europe and Africa

-0.013 (0.002 SE) units/year; southern Europe, -0.009 (0.001 SE) units/year; Africa, -0.007 (0.002 SE) units/year (all estimates were significantly different from $0, P$ values always <0.006). The mean index significantly differed between areas (Table 1), with increasing values from northern Europe [estimated marginal mean, 0.27 (0.03 SE)] to central [0.48 (0.03 SE)] and southern Europe and Africa [(0.72 (0.03 SE in both cases)] (post hoc tests, Africa vs southern Europe: $P=0.95$; all other pairwise comparisons: $P<0.001$; the $F$-test of the effect of geographic area based on the linearly independent pairwise comparisons among the estimated marginal means had the following statistics: $F_{3,52}=51.7, P<0.001$ ).

All the results concerning the grey heron were qualitatively unchanged if the analysis was restricted to wintertime recoveries (September-February; details not shown). Analyses for the other species, carried out without geographic distinctions due to sample size limitations (see "Materials and methods") revealed similar generalized temporal declines in the human-induced mortality index (Fig. 5b) that were statistically significant in all cases, ranging from -0.023 units/year for the little egret (corresponding to a $11.5 \%$ decline in human-induced mortality per 
Table 1 Weighted least-squares analyses of covariance models of temporal changes in the "human-induced mortality"; $R^{2}$ refers to the variance explained by the whole model

\begin{tabular}{llrlllll}
\hline Species & Variables & $F$ & $d f$ & $P$ & Estimate (SE) & $R^{2}$ \\
\hline Grey heron & Area & 50.8 & 3,55 & $<0.001$ & & \\
& Year $^{\mathrm{a}}$ & 134.2 & 1,55 & $<0.001$ & $-0.009(0.001)$ & 0.87 \\
Purple heron & Year $^{\mathrm{a}}$ & 16.3 & 1,12 & 0.002 & $-0.007(0.002)$ & 0.58 \\
Little egret & Year $^{\mathrm{c}}$ & 48.9 & 1,9 & $<0.001$ & $-0.023(0.003)$ & 0.85 \\
$\begin{array}{c}\text { B-c night } \\
\text { heron }\end{array}$ & Year $^{\mathrm{b}}$ & 7.9 & 1,8 & 0.023 & $-0.012(0.004)$ & 0.50 \\
Cattle egret & Year $^{\mathrm{b}}$ & 18.1 & 1,8 & 0.003 & $-0.011(0.003)$ & 0.69 \\
Great egret & Year $^{\mathrm{b}}$ & 8.4 & 1,6 & 0.027 & $-0.011(0.004)$ & 0.58 \\
\hline
\end{tabular}

Timeframes: ${ }^{\mathrm{a}} 1926-2005,{ }^{\mathrm{b}} 1956-2005,{ }^{\mathrm{c}} 1951-2005$

5-year period over the selected timeframe) to -0.007 units/ year for the purple heron (a 3.5\% decline in human-induced mortality per 5-year period) (Table 1).

Factors affecting population dynamics

Cross-correlation analyses between TR and APII of each species and the environmental variables showed some significant associations, thus identifying the predictors to be tested in ARIMA models (Table 2).

Specifically, for the grey heron, the cross-correlation function (CCF) between TR and predictor variables uncovered significant positive associations with "winter temperature Italy" and with the availability of ricefields, while a negative association was found with "humaninduced mortality" of the previous 5 years (Table 2). No significant association was found between environmental variables and APII (Table 2). The best-fitting ARIMA models for this species identified a negative effect of the human-induced mortality on population trend, while winter temperatures had a positive effect (Table 3). ARIMA models including availability of ricefields did not contribute to explain the population trend $(\triangle \mathrm{AICc}>2)$ and were thus discarded.

For the little egret, CCF showed a significant association of the TR with "Rain Italy" and with the availability of ricefields, while only "Rain Italy" was associated with APII (Table 2). The ARIMA model highlighted a weak positive effect of late winter-early spring rainfall, but the most important environmental variable driving the observed increase of the species was the availability of ricefields (Table 3 ).

Among the migrant species, the population variation of the purple heron did not show any association with either one of the three factors, so no ARIMA model was produced. On the other hand, the CCF analysis showed a positive association of the squacco heron APII with "subSahara rain" with a delay of 1 year (Table 2). Multimodel
Table 2 Cross-correlations between TRIM residuals (TR) or annual proportional increase index (APII, see "Materials and methods" for definitions) of heron and egret species and selected environmental variables

\begin{tabular}{|c|c|c|}
\hline Predictors tested & TR & APII \\
\hline \multicolumn{3}{|l|}{ Grey heron } \\
\hline Ricefields & $0.36(0)^{*}$ & $-0.24(0)$ \\
\hline Human-induced mortality & $-0.40(5)^{*}$ & $0.20(0)$ \\
\hline Rain Italy & $-0.25(0)$ & $-0.21(1)$ \\
\hline Winter temperature Italy & $0.43(1)^{*}$ & $-0.22(0)$ \\
\hline \multicolumn{3}{|l|}{ Little egret } \\
\hline Ricefields & $0.35(0)^{*}$ & $-0.17(4)$ \\
\hline Human-induced mortality & $0.16(1)$ & $0.23(2)$ \\
\hline Rain Italy & $-0.35(1)^{*}$ & $-0.34(0)^{*}$ \\
\hline Winter temperature Italy & $-0.31(1)$ & $-0.28(0)$ \\
\hline \multicolumn{3}{|l|}{ Purple heron } \\
\hline Ricefields & $0.33(0)$ & $0.04(2)$ \\
\hline Human-induced mortality & $0.18(3)$ & $-0.27(5)$ \\
\hline Rain Sahel & $0.23(2)$ & $-0.29(5)$ \\
\hline Sub-Saharan rain & $-0.27(0)$ & $0.24(0)$ \\
\hline \multicolumn{3}{|l|}{ Squacco heron } \\
\hline Ricefields & $0.27(4)$ & $-0.16(1)$ \\
\hline Human-induced mortality & $-0.14(4)$ & $0.23(0)$ \\
\hline Rain Sahel & $0.23(2)$ & $0.19(0)$ \\
\hline Sub-Saharan rain & $0.23(1)$ & $0.46(1)^{*}$ \\
\hline \multicolumn{3}{|l|}{ B-c night heron (1972-1988) } \\
\hline Ricefields & $-0.25(0)$ & $0.36(0)$ \\
\hline Human-induced mortality & $0.16(4)$ & $-0.38(4)$ \\
\hline Rain Sahel & $0.34(3)$ & $0.53(0)^{*}$ \\
\hline Sub-Saharan rain & $-0.48(5)$ & $0.46(4)$ \\
\hline \multicolumn{3}{|l|}{ B-c night heron (1989-2006) } \\
\hline Ricefields & $-0.82(5)^{*}$ & $-0.46(2)$ \\
\hline Human-induced mortality & $0.51(3)^{*}$ & $0.25(3)$ \\
\hline Rain Sahel & $-0.46(3)$ & $-0.48(0)$ \\
\hline Sub-Saharan rain & $-0.69(0)^{*}$ & $0.36(3)$ \\
\hline Grey heron population size & $-0.56(4)^{*}$ & $0.06(0)$ \\
\hline Little egret population size & $-0.72(2)^{*}$ & $0.23(0)$ \\
\hline Herons and egrets population size & $-0.68(2)^{*}$ & $0.12(0)$ \\
\hline
\end{tabular}

The stronger correlation coefficient for each variable and the corresponding lag (number of years; in parentheses) are shown

$* P<0.05$

inference outlined a weak effect of this variable (Table 3). Finally, for the black-crowned night heron, no significant association was found when the entire time series was considered (details not shown). We thus split the series in 1988, the year at which the TRIM model identified a change from an increasing trend to a decreasing one. Because the two semi-series were rather short, correlations with incremental lags were tested by the Spearman non-parametric correlation test. For the period of 
Table 3 ARIMA models for each heron species, with model inference criteria

\begin{tabular}{|c|c|c|c|c|c|}
\hline $\begin{array}{l}\text { Auto-regression } \\
\text { coefficient (SE) }\end{array}$ & ARIMA model predictors & $\begin{array}{l}\text { Maximized } \\
\text { log-likelihood }\end{array}$ & $\begin{array}{l}\text { Number of } \\
\text { parameters }\end{array}$ & $\mathrm{AICc}$ & $\Delta \mathrm{AICc}$ \\
\hline \multicolumn{6}{|l|}{ Grey heron } \\
\hline $1.0(0.02)$ & Human-induced mortality ${ }^{a}$ & 31.591 & 4 & -50.840 & 0.00 \\
\hline $1.0(0.02)$ & Human-induced mortality + winter temperature Italy ${ }^{\mathrm{b}}$ & 30.220 & 5 & -50.683 & 0.16 \\
\hline $1.0(0.02)$ & Winter temperature Italy & 29.287 & 4 & -48.974 & 1.87 \\
\hline \multicolumn{6}{|l|}{ Little egret } \\
\hline $0.7(0.12)$ & Ricefields $^{c}$ & 31.110 & 4 & -52.791 & 0.00 \\
\hline $0.7(0.12)$ & Ricefields + rain Italy ${ }^{\mathrm{d}}$ & 31.683 & 5 & -51.144 & 1.65 \\
\hline \multicolumn{6}{|l|}{ Squacco heron } \\
\hline $0.6(0.13)$ & - & 1.973 & 3 & 2.854 & 0.00 \\
\hline $0.6(0.13)$ & Sub-Sahara rain ${ }^{\mathrm{e}}$ & 3.049 & 4 & 3.331 & 0.73 \\
\hline \multicolumn{6}{|c|}{ B-c night heron (1972-1988) } \\
\hline $0.8(0.17)$ & - & -6.603 & 3 & 21.206 & 0.00 \\
\hline $0.9(0.15)$ & Rain Sahel ${ }^{\mathrm{f}}$ & -4.792 & 4 & 21.220 & 0.01 \\
\hline \multicolumn{6}{|c|}{ B-c night heron (1989-2006) } \\
\hline $0.79(0.17)$ & Grey heron population size ${ }^{\mathrm{g}}$ & 9.006 & 4 & -6.935 & 0.00 \\
\hline
\end{tabular}

Only top models that added substantial information to the trend $(\triangle \mathrm{AICc}<2)$ are shown for each species. Predictors were selected on the basis of the significance of cross-correlation analyses (see "Materials and methods"). A null model (without predictors) was always tested. Delay, multimodel averaged regression estimate $\hat{\bar{B}}$ and predictor relative importance $(\Sigma w)$, are shown in the following footnotes

${ }^{\mathrm{a}}$ Delay $=5$ years, estimate $(\mathrm{SE})=-0.490(0.205), \Sigma w=0.830$

${ }^{\mathrm{b}}$ Delay $=1$ year, estimate $(\mathrm{SE})=0.010(0.006), \Sigma w=0.569$

${ }^{\mathrm{c}}$ Delay $=0$ year, estimate $(\mathrm{SE})=0.001\left(2.1 \times 10^{-4}\right), \Sigma w=0.978$

${ }^{\mathrm{d}}$ Delay $=0$ year; estimate $(\mathrm{SE})=0.002(0.002), \Sigma w=0.314$

${ }^{\mathrm{e}}$ Delay $=1$ year, estimate $(\mathrm{SE})=0.027(0.018), \Sigma w=0.464$

${ }^{\mathrm{f}}$ Delay $=0$ year; estimate $(\mathrm{SE})=0.287(0.154), \Sigma w=0.498$

$\mathrm{g}$ Delay $=4$ years, estimate $(\mathrm{SE})=-1.088(0.274), \Sigma w=0.690$

population increase, correlation analysis showed a weak positive association of the APII with "Rain Sahel" with no delay (Table 2). During the decreasing phase, on the other hand, significant correlations were found between TR and the availability of ricefields, the human-induced mortality and the "sub-Sahara rain" (Table 2). Since none of these variables improved the ARIMA model fit ( $\triangle \mathrm{AICc}>2$ compared to the null model), in order to explore the possible causes of such decline, we tested whether the decreasing trend could be related to the intensity of interspecific competition for food or space within the heron and egret guild. As proxies of the intensity of intraguild competition, we considered the abundance of the two main potential competitors (grey heron and little egret), as well as the overall population size of all species (herons and egrets population size). We found significant negative associations between TR all the three candidate predictors, with variable delays (Table 2). However, only population size of the grey heron improved the fit of the model describing the decreasing black-crowned night heron trend, whereas all other models showed a $\triangle \mathrm{AICc}>2$ (Table 3$)$.

\section{Discussion}

The trends of heron and egret populations in NW Italy during the past 35 years were strikingly smooth and directional. Four species (grey, purple and squacco heron, and little egret), after an initial marked increase, leveled off around year 2000, with population levels 3-23 times higher than the initial level. The black-crowned night heron, while initially increasing like the other species, reversed its trend later on, and at the end of the 1980s dropped back to the former levels. The two new colonizers, the cattle egret and the great egret, showed early trends of increase that fit an apparently exponential increase or the initial phase of a logistic increase, a pattern typical for species expanding into a new region (e.g., the cattle egret; Kushlan and Hafner 2000; Kushlan and Hancock 2005).

Our long-term study contributes to the broad picture of recent heron population trends in Europe, which can be summarized as follows. In the early part of the twentieth century, several European heron populations were at a minimum, due to persecution as pests of freshwater fisheries and as game species, but many subsequently 
recovered (Marion 1997; Kushlan and Hafner 2000; Kushlan and Hancock 2005). During the last four decades of the century, the resident grey heron, and the partially migratory little egret, showed a marked and coherent increase throughout southern Europe (Marion 1997; Tourenq et al. 2000; Campos and Fernnández-Cruz 2006), although the grey heron remained relatively stable in central-northern Europe (Marchant et al. 2004; Schmid et al. 2004). On the other hand, the migratory blackcrowned night heron and purple heron showed completely different trends among different European regions, suggesting that local rather than global factors mostly affected population dynamics of these species (Fasola et al. 2000).

Our analyses indicate that some of the candidate environmental factors could play a role in explaining variability of heron populations in NW Italy. Specifically, the ARIMA models showed that high winter temperatures positively affected breeding numbers of resident grey herons, while high rainfall in the Sahel positively affected breeding numbers of the migratory squacco and black-crowned night herons (the latter only in the early period of population increase). The effects of African rainfall on population variation of migrant species was, however, rather weak, as could be judged by the relatively low weights and large SEs associated with parameter estimates (Table 3). On the other hand, the generalized temporal decline in the humaninduced mortality index that occurred in the course of the twentieth century, which was observed for all species and may indicate a temporal decline in the impact of hunting and trapping activities (e.g., McCulloch et al. 1992; Barbosa 2001), only had a positive effect on grey heron populations. Finally, breeding numbers of the little egret were positively affected by the increase of ricefields throughout the study period.

The effects of climate variation on heron populations were similar to those observed in previous studies. Grey heron breeding numbers are well known to respond to winter severity (Marchant et al. 2004), as the survival of first-year birds is strongly reduced by prolonged late winter and early spring cold spells (North and Morgan 1979). It is also worth noting that the population increase of the grey heron, the only species whose population trend was positively related to winter temperatures, was concomitant with the increase in winter temperatures throughout the study period and in the study area (average increase of mean winter temperature anomalies was $0.07^{\circ} \mathrm{C} /$ year $(0.03 \mathrm{SE}$, $t=2.36, P=0.025)$, suggesting that ongoing climate warming may play a role in affecting population dynamics of this species.

The effect of early spring rainfall on heron population dynamics was less clear. This variable was retained only in the final ARIMA model for the little egret, with a positive coefficient, but the SE of the coefficient was as large as the estimate (Table 3), thus denoting an unclear effect. Spring rainfall was previously shown to affect breeding numbers and productivity of little and cattle egrets, and of squacco herons breeding in natural coastal wetlands, mainly via an increase in the extent of suitable foraging habitats (Hafner et al. 1992, 2001, 2002; Bennetts et al. 2000). It might thus be speculated that the effect of spring rainfall on population dynamics is stronger in natural wetlands than in 'artificial' wetlands such as ricefields, whose extension is relatively unaffected by rainfall variation compared to natural wetlands.

Diminished human-related mortality was hypothesized as the major cause of grey heron increase in France (Marion 1997). Our analysis of human-induced mortality of herons and egrets suggests a decrease in hunting-related mortality in the course of the twentieth century, which occurred throughout all Europe but was more pronounced in the south. This decrease in mortality could be related to population increase of the grey heron in NW Italy. The temporal decrease in hunting mortality (Fig. 5) kept pace with enforcement of legal protection (e.g., France, little egret in 1962, all species in 1975; Italy, all species in 1977; Spain, all species in 1981; Marion 1997; Kushlan and Hafner 2000). For other bird groups as well, the change in status from quarry to protected resulted in a decrease in hunting impact (e.g., waders in Spain; Barbosa 2001). Hunting indexes for 20 species of raptors and passerines were higher in Mediterranean countries than in the rest of Europe, and a long-term decrease occurred after 1980 for several species, but not for the legitimate quarry species (McCulloch et al. 1992). A decrease in human-induced mortality as estimated from ring recoveries is further supported by the results of studies based on other methods (e.g., questionnaire surveys and number of hunting permits; Massa and Bottoni 1989; Magnin 1991). Despite being significantly related to population variation of the grey heron only, it is however suggestive that the generalized population increase of most species during 1985-2000 in NW Italy (with the exception of the black-crowned night heron) followed, with a short delay, the sharp decrease in human-induced mortality that took place mainly in southern Europe, where hunting pressure on herons was probably heavier than elsewhere (see Fig. 5a).

Changes in foraging habitats were shown to affect populations of herons and egrets in southern France (Tourenq et al. 2000). Similarly, the population increases of the little egret in NW Italy were mainly driven by a concomitant increasing availability of ricefields, the main foraging habitat of herons and egrets (Fasola 1986, 1994). This effect might seem surprising, because the quality of ricefields as heron foraging habitat may have declined since the late 1980s, due to increasing cultivation of rice on dry fields, which provides unsuitable foraging habitats for 
herons (Boncompagni and Fasola 2005; M. Fasola, unpublished data). It is thus possible that the overall increase of traditionally flooded ricefields overrode the increase of dry ricefields. Moreover, dry ricefields are eventually flooded later in the season (Fasola and Ruiz 1996b), and thus the decline in the quality of foraging habitats due to the expansion of dry rice cultivations may not have been so important in determining changes in heron populations.

Interestingly, intra-guild competition for resources with the grey heron was the only factor that explained the recent decrease of the black-crowned night heron, a unique trend that contrasts with the concomitant increase of the other six study species. Differently from the earlier period, the recent trend of this species was not related to rainfall in the African wintering quarters. Niche overlap for prey type and size, and for foraging habitats, is greater between blackcrowned night and grey herons than between any of the other species of herons and egrets (Fasola 1986, 1994), thus supporting the idea that black-crowned night herons could have been limited by the strong numerical increase of the larger and competitively superior grey heron.

At the colony-level scale, main foraging habitats surrounding the colony site, and colony protection status, were both shown to significantly affect population trends. Despite some variability, the grey and purple herons showed a population increase in non-rice field sectors throughout the study period (Figs. 3, S2 in ESM). In ricefields, grey heron populations showed a marked increase before the 1997 change point, but levelled off afterwards; the purple heron instead showed a relative stability throughout the study period, though with a tendency to increase after the 1993 change point (Figs. 3, S2). No clear patterns emerged for the black-crowned night heron (Figs. 3, S2). Variation in population trends according to protection status were relatively more coherent among species, showing an initial stage of faster population increase in protected colonies, while after the last change point, the population increase was faster in nonprotected sites (Figs. 4, S3).

On the whole, such patterns are due to range expansion, and to settlement of new colonies that took place following population increase. After the mid-1990s, the relative population increase was greater in the newly colonized areas, i.e., the rivers and the upland sectors where the new colonies still remain mostly unprotected, while the traditionally occupied area (i.e., the rice field sector where most protected colonies are settled) experienced a relatively smaller increase, albeit hosting a greater absolute number of nests (Figs. S2, S3).

In the study area, special reserves were set up to protect heronry sites by the local administrations, mostly in 1985 and 1990 (Fasola et al. 2007). However, some degree of protection was granted to many colonies even before the mid-1980s, and population increases started before any implementation of legal protection measures of colony sites. Thus, colony site protection does not seem to have been the primary trigger of population increase of herons and egrets in NW Italy, although it is obviously important for the long-term viability of the populations.

Among the other possible factors driving the observed population increases, temporal changes in breeding productivity and decreases in contaminant load (Newton et al. 1993) might be considered. However, the productivity of little egret and black-crowned night heron actually decreased in a sample of focal colonies of our study area during population increase from 1988 to 2001 (Fasola 1998; M. Fasola, unpublished data from 1996 to 2001). A similar negative relationship of nesting success with total number of nests was found for little egret (Bennetts et al. 2000), and for squacco heron clutch size, that decreased when population increased (Hafner et al. 2001). Moreover, residues of heavy metals, organochlorines, and PCBs in the eggs of egrets and of herons in NW Italy were already below the levels affecting survival or reproduction during the late 1970s, well before the population increase (Fasola et al. 1987, 1998).

In conclusion, our study suggests that the recent population increase of resident herons and egrets in NW Italy have been partly shaped by environmental and climatic changes, as well as by temporal changes in human influence, whereas the population trends of two migratory species were partly explained by climate in the wintering areas. Although our results are suggestive of a role for some extrinsic factors in driving population trends, the task of discovering biologically relevant factors of population regulation remains unfortunately hindered by fundamental methodological difficulties (see, e.g., Jonzén et al. 2001). Importantly, population dynamics cannot be fully explained unless the underlying demographic mechanisms are properly known (Yamamura et al. 2006), which could not be the case in the present study. Therefore, further monitoring programs aimed at scrutinizing the factors driving population variations should address the impacts of productivity, survival, and proportion of breeders on population dynamics, all of which are essential for the understanding of population regulation of bird species (Newton 1998).

Acknowledgments We are deeply indebted to all the collaborators of the research group Garzaie Italia who performed the censuses at the colonies over the years, and to the Regione Lombardia for its support. We are grateful to the European Union for Bird Ringing (EURING) which made the recovery data available, and to the many ringers and ringing scheme staff who have gathered and prepared the data. Chris du Feu helped with the EURING Data Bank, Moreno Cassano (ARPA Lombardia) with meteorological data, and Nicola 
Gilio with the maps. Francisco Campos, Michael Gauthier-Clerc, Savas Katzantzidis, Tibor Mikuska, and Hans Schmid kindly provided information on population fluctuations for their countries. We thank Roger Jovani, David Serrano and an anonymous referee for constructive criticism on a previous version of the manuscript. Our remembrance goes to the late friends Heinz Hafner and Francesco Barbieri with whom we shared so many years in the field and in discussions.

\section{References}

Anderson DR, Burnham KP, Thompson WL (2000) Null hypothesis testing: problems, prevalence and an alternative. J Wildl Manage 64:912-923

Barbosa A (2001) Hunting impact on waders in Spain: effects of species protection measures. Biodivers Conserv 10:1703-1709

Barbraud C, Hafner H (2001) Variations des effectifs nicheurs de Heron Pourprés Ardea purpurea sur le litoral francais en relation avec la pluviometrie sur les quartiers d'hivernage. Alauda 69:29-36 (in French with English abstract)

Bennetts RE, Fasola M, Hafner H, Kayser Y (2000) Influence of environmental and density-dependent factors on reproduction of Little Egrets. Auk 117:634-639

Bethke RW, Nudds TD (1995) Effects of climate change and land use on duck abundance in Canadian prairie-parklands. Ecol Appl 5:588-600

Böhning-Gaese K, Lemoine N (2004) Importance of climate change for the ranges, communities and conservation of birds. Adv Ecol Res 35:211-236

Boncompagni E, Fasola M (2005) Ecologia delle "rane verdi" nelle risaie italiane e relazioni con le altre componenti faunistiche. Vercelli, Italy: Assessorato Agricoltura della Provincia. Le rane in risaia, tradizione, scienza e risorse: 25-29 (in Italian)

Both C, Bouwhuis S, Lessells CM, Visser ME (2006) Climate change and population declines in a long-distance migratory bird. Nature 441:81-83

Box GEP, Jenkins GM (1976) Time series analysis: forecasting and control. Prentice Hall, Englewood Cliffs

Burnham KP, Anderson DR (2002) Model selection and multi-model inference. A practical information-theoretic approach, 2nd edn. Springer, New York

Campos F, Fernnández-Cruz M (2006) La Garza Real en Espaňa. I Población reproductora (1950-2000). Ser Zool Publ Biol Univ Navarra 30:1-118 (in Spanish with English abstract)

Cramp S, Simmons KEL (1977) The birds of the Western Paleartic, vol 1. Oxford University Press, Oxford

Crick HPQ (2004) The impact of climate change on birds. Ibis 146(Suppl 1):48-56

Donald PF, Green RE, Heath MF (2001) Agricultural intensification and the collapse of Europe's farmland bird populations. Proc R Soc Lond B 268:25-29

Duhem C, Roche P, Vidal E, Tatoni T (2008) Effects of anthropogenic food resources on yellow-legged gull colony size on Mediterranean islands. Popul Ecol 50:91-100

Fasola M (1986) Resource use of foraging herons in agricultural and nonagricultural habitats in Italy. Col Waterbirds 9:139148

Fasola M (1994) Opportunistic use of foraging resources by heron communites in Southern Europe. Ecography 17:113-123

Fasola M (1998) Optimal clutch size in herons: observational and experimental approaches. Ethol Ecol Evol 10:33-46

Fasola M, Alieri R (1992) Conservation of heronry sites in North Italian agricultural landscapes. Biol Conserv 62:219-228
Fasola M, Hafner H (1997) Nycticorax nycticorax Night Heron. BWP Update 1:157-165

Fasola M, Ruiz X (1996a) The value of rice fields as substitutes for natural wetlands for waterbirds in the Mediterranean Region. Col Waterbirds 19 (Special publication 1):122-128

Fasola M, Ruiz X (1996b) Rice farming and waterbirds: integrated management in an artificial landscape. In: Pain DJ, Pienkowski MW (eds) Farming and birds in Europe: the common agricultural policy and tis implication for bird conservation. Academic, London, pp 210-235

Fasola M, Vecchio I, Caccialanza G, Gandini C, Kitzos M (1987) Trends of organochlorine residues in eggs of birds from Italy, 1977 to 1985 . Environ Pollut 48:25-36

Fasola M, Movalli A, Gandini C (1998) Heavy metal, organochlorine pesticide, and PCB residues in eggs and feathers of herons breeding in northern Italy. Arch Environ Contam Toxicol 34:8793

Fasola M, Hafner H, Prosper P, van der Kooij H, Schogolev IV (2000) Population changes in European herons in relation to African climate. Ostrich 71:52-55

Fasola M, Albanese G, ASOER, Boano G, Boncompagni E, Bressan U, Brunelli M, Ciaccio A, Floris G, Grussu M, Guglielmi R, Guzzon C, Mezzavilla F, Paesani G, Sacchetti A, Sanna M, Scarton F, Scoccianti C, Utmar P, Vaschetti G, Velatta F (2007) Le garzaie in Italia, 2002. Avocetta 31:5-46 (in Italian with English abstract)

Gaston KJ, Blackburn TM, Goldewijk KK (2003) Habitat conversion and global avian biodiversity loss. Proc R Soc Lond B 270:1293-1300

Guisan A, Edwards TC Jr, Hastie T (2002) Generalized linear and generalized additive models in studies of species distributions: setting the scene. Ecol Model 157:89-100

Hafner H, Pineau O, Wallace JP (1992) The effects of winter climate on the size of the Cattle Egret (Bubulcus ibis L.) population in the Camargue. Terre Vie 47:403-410

Hafner H, Bennetts RE, Kaiser Y (2001) Changes in clutch size, brood size and numbers of nesting Squacco Herons Ardeola ralloides over a 32-year period in the Camargue, southern France. Ibis 143:11-16

Hafner H, Fasola M, Voisin C, Kayser Y (2002) Egretta garzetta Little Egret. BWP Update 4:1-20

Johnson DH (1999) The insignificance of statistical significance testing. J Wildl Manage 63:763-772

Jonzén N, Lundberg P, Ranta E, Kaitala V (2001) The irreducible uncertainty of the demography-environment interaction in ecology. Proc R Soc Lond B 269:221-225

Kushlan JA, Hafner H (2000) Heron conservation. Academic, San Diego

Kushlan JA, Hancock JA (2005) The Herons. Oxford University Press, Oxford

Lande R, Engen S, Sæther BE (2003) Stochastic population dynamics in ecology and conservation. Oxford University Press, Oxford

Magnin G (1991) Hunting and persecution of migratory birds in the Mediterranean region. ICBP Tech Publ 12:63-75

Marchant JH, Freeman SN, Crick HQP, Beaven LP (2004) The BTO heronries census of England and Wales 1928-2000: new indexes and a comparison of analytical methods. Ibis 146:323-334

Marion L (1997) Évolution des effectifs nicheurs et de la répartition des hérons coloniaux en France entre 1974 et 1994. Alauda 65:86-88 (in French)

Massa R, Bottoni L (1989) The killing of passerine migrant birds in Italy. Sitta 3:27-36

McCulloch MN, Tucker GM, Baillie SR (1992) The hunting of migratory birds in Europe: a ringing recovery analysis. Ibis 134((Suppl 1)):55-65 
Møller AP, Rubolini D, Lehikoinen E (2008) Populations of migratory bird species that did not show a phenological response to climate change are declining. Proc Natl Acad Sci USA 105:16195-16200

Moltoni E (1936) Le garzaie in Italia. Rivista Italiana Ornitologia 6:109-148, 211-296 (in Italian)

Newton I (1998) Population limitation in birds. Academic, London

Newton I, Wyllie I, Asher A (1993) Long-term trends in organochlorine and mercury residues in some predatory birds in Britain. Environ Pollut 79:143-151

North PM, Morgan BJT (1979) Modelling heron survival using weather data. Biometrics 35:667-681

Pannekoek J, van Strien A (2001) TRIM 3 manual (trends and indexes for monitoring data). Statistics Netherlands, Voorburg

Perrins CM, Lebreton J-D, Hirons GJM (1993) Bird population studies. Oxford University Press, Oxford

Reif J, Vorisek P, Stastny K, Koschova M, Bejcek V (2008) The impact of climate change on long-term population trends of birds in a central European country. Anim Conserv 11:412-421

Sæther BE, Sutherland WJ, Engen S (2004) Climate influences on a population dynamics. Adv Ecol Res 35:185-209

Sæther BE, Lillegård M, Grøtan V, Drever MC, Engen S, Nudds TD, Podruzny KM (2008) Geographical gradients in the population dynamics of North American prairie ducks. J Anim Ecol 77:869882

Schmid H, Volet B, Thoma M (2004) Situation actuelle du Heron cendré Ardea cinerea en Suisse et évolution des effectifs depuis 1980. Nos Oiseaux 51:85-93 (in French with English abstract)
Seavy NE, Dybala KE, Snyder MA (2008) Climate models and ornithology. Auk 125:1-10

Speek G, Clark JA, Rhode Z, Wassenaar RD, VanNooordwijk AJ (2006) The EURING exchange-code 2000. EURING website http://www.euring.org

Stenseth NC, Mysterud A, Ottersen G, Hurrell JW, Chan K-S, Lima M (2002) Ecological effects of climate fluctuations. Science 297:1292-1296

Tourenq C, Bennetts RE, Sadoul N, Mesleard F, Kayser Y, Hafner H (2000) Long-term population and colony patterns of four species of tree-nesting herons in the Camargue, South France. Waterbirds 23:236-245

Tucker GM, Heath MF (1994) Birds in Europe: their conservation status. BirdLife International, Cambridge

van der Winden J, Poot M, van Horssen P (2008) The migration of the Purple Heron. http://www.buwa.nl

van Strien A, Pannekoek J, Hagemeijer W, Verstrael, T (2004) A loglinear Poisson regression method to analyse bird monitoring data. In: Anselin A (ed) Bird numbers 1995. In: Proceedings of the international conference and 13th meeting of the European Bird Census Council, Pärnu, Estonia. Bird Census News 13:33-39

Viljugrein H, Stenseth NC, Smith GW, Steinbakk GH (2005) Density dependence in North American ducks. Ecology 86:245-254

Yamamura K, Yokozawa M, Nishimori M, Ueda Y, Yokosuka T (2006) How to analyze long-term insect population dynamics under climate change: 50-year data of three insect pests in paddy fields. Popul Ecol 48:31-48 